\title{
Sustainability and IS Research - An Interaction Design Perspective
}

\author{
Gitte Skou Petersen \\ Department of Informatics, Copenhagen Business School \\ Howitzvej 60, 5. sal. 2000 Frederiksberg, Denmark \\ Tel.: (+45) 24676744 \\ gsp.inf@cbs.dk
}

\begin{abstract}
The intention of this paper is to propose interaction design as a venue for IS research into sustainability and in that connection also propose a new theoretical psychological approach to interaction design. This new theoretical psychological framework is based on ecological psychology and activity theory. The paper will outline the scientific demands for the framework as well as the frameworks focus areas that are: 1) Intentional-motivational aspects of interaction 2) Sensory-motor aspects of interaction 3) Behavior-context aspects of interaction. Furthermore the paper will briefly present a design science research project applying the framework to interaction design for a climate management ICT system in greenhouses.
\end{abstract}

Keywords: Sustainability, Interaction design, IS research, Activity theory, Ecological psychology, HWID.

\section{Introduction}

Sustainability has the attention of the public eye and the debate typically centers on topics like global warming, sustainable agriculture and renewable energy sources. The role of information systems and IS research in dealing with the challenges of sustainability could be important, but as researchers point out then sustainability within IS research is presently only an emerging focus (Melville, 2010; Watson et al., 2010). This paper suggests interaction design as an IS research approach to sustainability. As an example saving energy, and avoiding to waste energy, has been investigated in relation with interaction design of domestic technology. In an experiment well-designed feedback in domestic central heating systems have been found to support users in achieving both efficient energy use as well as energy waste level reduction (Wastell et al., 2009). Likewise an interaction design experiment resulted in savings when the users were supported in setting goals for the energy usage of a washing machine (McCalley \& Midden, 2002). These experimental results suggest that interaction design actively supporting user intentions in regard with energy usage can be one viable approach to sustainability for IS research.

The first point promoted by this paper is therefore that interaction design can contribute to attaining efficiency in energy consumption both in domestic and professional settings. A second point that will be presented is that a development of 
the theoretical approach to interaction design is necessary to allow for a further scientific development of the field. Currently the interaction design field suffers from two problems 1) Commonsensical guidelines often guides interaction design e.g. Normans guidelines of visibility or feedback (Norman, 1998). Scientifically it is presently necessary to mature the field further and analyze what the guidelines mean in term of human behavior. 2) Research on interaction design has followed the technological development and is organized by technologies instead of by human behavioral characteristics.

Both of these problems can be addressed by introducing a unified theoretical approach to human-artefact interaction. This will provide both a structured scientific approach to interaction design and allow for the generalization and transfer of knowledge of human behavioral characteristics across technological niches. The concept of 'artefact' is used as an umbrella term and refers to man-made objects including both material and abstract objects. This will be elaborated upon in the next part of the paper.

This paper will first outline the scientific demands for a new theoretical approach to interaction design grounded in psychological theory and then the outline will be followed by a presentation of the contents of such a new theoretical psychological framework. As a conclusion the research project, where the framework will be applied, is briefly described.

\section{The Scientific Demands for a New Theoretical Approach to Interaction Design}

Since human (hominid) tool-use has been around for literally millions of years it means that human-artefact interaction is as much a product of our evolutionary development as are our perceptual systems and our social and cognitive abilities (Leontyev, 2009). From an activity theoretical standpoint: "The development of activity brings us into closer and closer contact with still greater parts of, and still more layers of the world - it makes increasingly more of the world into objects for us" (Mammen, 1989, p.86) meaning that during evolutionary development of animals the animal-environment interaction has become increasingly complex - so far culminating in the human-artefact interaction. Buchanan (1995) provides an illustrative example of the diversity of material and abstract objects we interact with. From the field of design thinking he makes a broad outline of 4 areas where design affects contemporary life 1) Symbolic and visual communications, e.g. graphic design, books, magazines, scientific illustration 2) Material objects, e.g. tools, instruments, clothing, machinery 3) Activities and organized services, e.g. logistics, logical decision making, strategic planning 4) Complex systems or environments for living, working, playing and learning, e.g. systems engineering, architecture, urban planning. An artefact today is therefore not only a physical, material thing, it can also be an abstract object (Gregor \& Jones, 2007) as information systems are an excellent example of. A theoretical psychological framework of human-artefact interaction can therefore not limit itself to addressing only material objects, but must also include abstract objects. 
Presently knowledge of interaction design is organized according to technological niche which is reasonable seen from the technological $R \& D$ point of view. The argument put forward here is that in order to further the research on interaction design then it is necessary to organize research around human behavioral characteristics instead. Even though there is great diversity in artefacts as illustrated by Buchanan (1995) then we, as human beings who interact with the technology, share common characteristics of perception, cognition and action that prevails regardless of technological niche. This line of argumentation is not new. Carroll (2003) concludes that the "golden age" of HCI was characterized by a unified theoretical approach cognitive science. Even though cognitive science has failed to fulfil the expectations and the field of HCI today is multidisciplinary and fragmented then there still is a need for a "comprehensive and coherent methodological framework" (p.7). The theoretical psychological framework put forward in this paper is an attempt to provide a coherent theoretical approach to human-artefact interaction and thereby interaction design. Dealing theoretically with the behavioral characteristics of human-artefact interaction, however, place certain demands on the framework:

Following the above mentioned arguments then a theoretical psychological framework firstly needs to concern itself with human-artefact interaction (in psychological terminology: the subject-object relationship) of both material and abstract objects across technological niches.

Secondly the framework has to be able to describe and analyze real world human behavior meaning human behavior as it occurs outside of the psychological laboratory. Cognitive psychology has long dominated psychology and "...presented us with a world not just devoid of things but also agents" (Costall \& Dreier, 2006, p.1). This does of course not mean that the full breath of psychological methodology including lab experiments will be rejected. It just means that the focus is on producing theory and models that accommodates the need for a field of applied psychology dealing with the nature of the human-artefact relationship as it unfolds in real-world settings.

Thirdly the framework has to encompass theoretical interdisciplinarity both within HCI but also with regard to psychological subdisciplines. Currently relevant knowledge is spread across research fields like IS, anthropology, HCI, design thinking, etc. but also across psychological subdisciplines like perception, cognition, and social psychology.

A theoretical psychological framework centered on three analytical focus areas is now constructed and it will address the above mentioned scientific demands.

\section{The Theoretical Psychological Framework}

The three analytical focus areas of the framework are based on the theoretical approaches to human-artefact interaction described by Bærentsen (2000) and Petersen (2005). This thereby allows for the theoretical stretch across different technological niches as well as it includes both material and abstract objects and the interactional differences they cause.

To ensure that the theoretical psychological framework allows for the description of real world user behavior it is based on activity theory and ecological psychology 
(Gibson, 1986; Leontyev, 2009; Schoggen, 1989) as these approaches focus on human behavior as it unfolds outside of the psychological laboratory. The laboratory as a main working area has been one of the main points of criticism directed at cognitive psychology along with the problems brought on by the paradigm of representationalism as interceding between the subject and the surrounding world (Carrol, 2003; Costall, 2007).

As this addresses two of the above mentioned scientific demands then the third demand for interdisciplinarity will be invoked within the individual focus areas thereby informing the framework of activity theory and ecological psychology with relevant knowledge from other theoretical perspectives.

The three focus areas are now briefly outlined. The framework will be further elaborated upon and tested during the course of the research project that is described in the last section of this paper.

\section{Motivational-intentional aspects of human-artefact interaction}

The motivational-intentional area concerns the part of the interaction that is purposeful and task-oriented on the user's behalf (Bærentsen, 2000). In short terms, this aspect of interaction addresses the work/task level of a given system. The functionalities have to be relevant to the user and also the user has to have a conceptual understanding of the system's functions in order to be able to use it. Key theoretical perspectives will be activity theory (Bærentsen, 2000; Leontyev, 2009), the HWID framework (Orngreen et al., 2008) as well as cognitive work analysis (Fidel \& Pejtersen, 2004; Vicente, 1999).

\section{Sensory-motor aspects of human-artefact interaction}

The sensory-motor aspects concerns the part of the interaction that are outside the user's conscious attentional focus e.g. object behavior in digital user interfaces such as changing the position of channels in a TV channel list (Bærentsen, 2000) or physical aspects of interaction such as tactile feedback in buttons (Wensveen et al., 2004). The importance of sensory-motor aspects for interaction is hereby stressed by making it an independent analytical focus area. Key theoretical perspectives will be activity theory (Bærentsen, 2000; Leontyev, 2009), ecological psychology (Gibson, 1986), embodied interaction (Dourish, 2001), human factors (Rasmussen, 1986; Rasmussen \& Vicente, 1987) and infant cognition research into core cognition (Kintzler \& Spelke, 2007) as well as application of core cognition theory to interaction design (Nørager, 2009)

\section{Behavior-context aspects of human-artefact interaction}

The behavior-context aspects of human-artefact interaction is introduced in order to enable an analysis of how behavior and context interacts as well as to define context in terms of human behavior. The behavior settings theory (Barker, 1968; Schoggen, 1989) - a little known theoretical contribution within the field of ecological social psychology - has through extensive empirical studies of children's behavior in their daily environment concluded that real world behavior has both structure and patterns. These structures and patterns interact with a given context making up what Roger G. Barker termed a behavior setting (Barker, 1968). Behavior settings theory will be a key theoretical perspective as it offers an understanding of context involving both objects and behavior (Petersen, 2005). 
The last section will briefly outline how the scientific demands and the framework are applied in an interaction design research project targeting climate control and efficient management of energy in green houses.

\section{The Research Project}

The project outlined here is a research project on interaction design that is a part of a Human Work Interaction Design (HWID) research project developing an internetand sensor-based ICT system for climate management in greenhouses (Clemmensen \& Pedersen, 2010; HWID webpage, 2011). Greenhouse growers use information systems for climate management in plant and vegetable production in greenhouses. Efficient management of energy consumption in this type of setting both concerns economic considerations as greenhouses are dependent on light, water and warmth, but also concerns optimization of growth without introducing stress conditions for the plants. This research project is a design science research projects methodology allows for a focus on the production of practically-oriented knowledge and therefore makes it possible to research an interaction design development process (Hevner et al., 2004; Wastell et al., 2009). Furthermore it also allows for research into real world user behavior and the project is therefore a design science research project where the artefact created is the interaction design for climate management software (Hevner et al., 2004).

The structure of the research design for this project is inspired by a design science research study where kernel theory, in the form of design principles, was first applied to interaction design and then evaluated and revised (Åkesson et al., 2010). In the same manner this project will apply a kernel theory to create interaction design for climate control software. As justificatory knowledge (kernel theory) to guide the interaction design the theoretical psychological framework will be developed, applied and evaluated (Gregor \& Jones, 2007).

The research project will consist of two main empirical components. One will be a work observation field study collecting knowledge of greenhouse growers work routines with regard to climate control as well as a mapping of the knowledge and technology involved in climate management. The knowledge gathered here will be channeled in to the second component that is the interaction design proposals for the new climate management ICT system.

Greenhouses are heavy consumers of energy resources and the climate management software and the associated technology that is used to control the energy consumption is becoming increasingly complex. This research project is itself a symptom, so to speak, of that tendency. The aim of this project - to develop an interaction design actively supporting user intentions to attain efficient energy usage - will therefore address if interaction design is a viable IS research approach to sustainability.

\section{References}

Barker, R.G.: Ecological Psychology. Stanford University Press, CA (1968)

Buchanan, R.: Wicked problems in design thinking. In: Margolin, V., Buchanan, R. (eds.) The Idea of Design, pp. 3-20. The MIT Press, Cambridge (1995) 
Bærentsen, K.B.: Intuitive user interfaces. Scandinavian Journal of Information Systems 12, 29-60 (2000)

Carroll, J.M.: Introduction: Toward a multidisciplinary science of human-computer interaction. In: Carroll, J.M. (ed.) HCI Models, Theories and Frameworks, pp. 1-9. Morgan Kaufmann Publishers, USA (2003)

Clemmensen, T., Pedersen, R.: A Human Work Interaction Design (HWID) perspective on Internet- and sensor based ICT system for climate management. In: NordiCHI 2010, Reykjavik, Iceland (October 16-20, 2010)

Costall, A.: How cognitive psychology highjacked thinking. Anthropological Psychology 18, 21-23 (2007)

Costall, A., Dreier, O.: Introduction. In: Costall, A., Dreier, O. (eds.) Doing Things with Things, pp. 1-12. Ashgate, UK (2006)

Dourish, P.: Where the action is. Bradford Book (2001)

Fidel, R., Pejtersen, A.M.: From information behaviour research to the design of information systems: the Cognitive Work Analysis framework. Information Research 10(1), paper 210 (2004), http://InformationR.net/ir/10-1/paper210.html (February 22, 2011)

Gibson, J.J.: The ecological approach to visual perception. Psychology Press, San Diego (1986)

Gregor, S., Jones, D.: The anatomy of a design theory. Journal of the Association for Information Systems 8(5), article 2, 312-335 (2007)

Hevner, A.R., March, S.T., Park, J., Ram, S.: Design science in information systems research. MIS Quarterly 28(1), 75-105 (2004)

HWID webpage (2011), http : / / hwid.cbs . dk/ (February 22, 2011)

Kintzler, K.D., Spelke, E.S.: Core systems in human cognition. In: von Hofsten, C., Rosander, K. (eds.) Progress in Brain Research, vol. 164, pp. 257-264 (2007)

Leontyev, A.N.: Activity and consciousness. Marxists Internet Archive (2009), http: / / www . marxists . org/archive/leontev/works/activityconsciousness.pdf (February 22, 2011)

Mammen, J.: The relationship between subject and object from the perspective of activity theory. In: Engelsted, N., Hem, L., Mammen, J. (eds.) Essays in General Psychology, Seven Danish Contributions, pp. 71-94. Århus University Press, Århus (1989)

McCalley, L.T., Midden, C.J.H.: Energy conservation through product-intergrated feedback: The roles of goal-setting and social orientation. Journal of Economic Psychology 23, 589$603(2002)$

Melville, N.P.: Information systems innovation for environmental sustainability. MIS Quarterly 34(1), 1-21 (2010)

Norman, D.A.: The design of everyday things. The MIT Press, Cambridge (1998)

Nørager, R.: Low level cognition in user interfaces. PhD-dissertation, University of Aarhus, Department of Psychology, Denmark (2009)

Orngreen, R., Mark Pejtersen, A., Clemmensen, T.: Themes in Human Work Interaction Design. In: Clemmensen, T. (ed.) Cultural Usability and Human Work Interaction Design Techniques that Connects: Proceedings from NordiCHI 2008 Workshop, CBS, Department of Informatics, Working paper no. 01-2008 (October 19, 2008)

Petersen, G.S.: Dealing with reality - in theory. In: Clemmensen, T., Nielsen, L. (eds.) Proceedings of the 5th Danish Human-Computer Interaction Research Symposium 2005, Copenhagen, November 8, pp. 74-79 (2005)

Rasmussen, J.: Information processing and Human-Machine Interaction. North Holland Series in Systems Science and Engineering, vol. 12. Elsevier Science Publishing Co., NY (1986)

Rasmussen, J., Vicente, K.J.: Cognitive control of human activities and errors: Implications for ecological interface design, Ris $\varnothing-\mathrm{M}-2660$. Ris $\varnothing$ National Laboratory, DK 4000 Roskilde, Denmark (1987)

Schoggen, P.: Behavior Settings. Stanford University Press, CA (1989) 
Vicente, K.J.: Cognitive work analysis. Lawrence Erlbaum Associate Publishers, New Jersey (1999)

Wastell, D., Sauer, J., Schmeink, C.: Time for a "design turn" in IS innovation research? A practice report from the home front. Information Technology \& People 22(4), 335-350 (2009)

Watson, R.T., Boudreau, M., Chen, A.J.: Information systems and environmentally sustainable development: Energy informatics and new directions for the IS community. MIS Quarterly 34(1), 23-38 (2010)

Wensveen, S.A.G., Djajadiningrat, J.P., Overbeeke, C.J.: Interaction Frogger: A design Framework to couple action and function through Feedback and Feedforward. In: DIS 2004, Cambridge, MA, USA (August 2004)

Åkesson, M., Kautz, K., Ihlström, C.: Engaged design science: Developing design visions for future E-newspaper. In: Thirty First International Conference on Information Systems, St. Louis (2010) 